\title{
Reimagining care: images of aging and creativity in House Calls and A Year at Sherbrooke
}

\author{
By SALLY CHIVERS*
}

\begin{abstract}
This article looks at the relationship between the esthetic and documentary commentaries offered by two National Film Board of Canada (NFB) productions, chosen because they use the documentary form to interpret aging and care in Canada for Canadians, offering a Canadian example of an issue that is of international importance. The first film, House Calls (Ian McLeod 2004), follows the work of Mark Nowaczynski, a physician who photographs his elderly patients to illustrate their dignity amidst what he perceives to be their fragility and vulnerability. The second, A Year at Sherbrooke (Thomas Hale 2009), follows artists Thelma Pepper and Jeff Nachtigall who work with residents of a Saskatoon long-term care facility - Pepper continues her longer term practice of photographing the residents and Nachtigall takes on a new role of artist-in-residence in which he mentors them in their own creative development. Analyzing the role of photography in each film, the article shows that, together, the films demonstrate that images of aging beyond mere decline may play a role in reimagining how care for older adults takes place.
\end{abstract}

* Sally Chivers, Department of English, Trent University, Ontario, Canada 
International Journal of Ageing and Later Life

Keywords: documentary film, photography, aging, care, creativity, Canada, Canadian healthcare.

As per the National Film Act of 1950, the National Film Board of Canada (NFB) has the mandate "to interpret Canada to Canadians and to other nations", which it has long attempted to fulfill by means of social documentary following founder John Grierson's plea to "[make] poetry where no poet has gone before" (1985: s. 9 a; 1979: 41). Statistics Canada predicts that the number of seniors (aged 65 and above) in Canada is likely to double between 2005 and 2056 (Turcotte \& Schellenberg 2006: 12). Not surprisingly, then, the aging of the population is increasingly of social, political, and cultural interest to Canadians. Older adults have long been important to NFB productions, not only as the interviewed witnesses of historical events featured in the social documentaries but also as a central topic in films, particular a number of films that focus on institutional and home care for seniors. ${ }^{1}$ Thus, it is in keeping with their tradition that two recent NFB documentary films about care deeply value older adults and/or residents of long-term care facilities and convey arguments about the current state of the Canadian care system. One portrays a doctor determined to make his services available to patients via house calls to extend their ability to live at home comfortably as long as possible. The other portrays an innovative long-term care residence that functions according to Eden Alternative principles to transform an institutional setting into a viable and desirable human habitat. ${ }^{2}$ Together, the films

${ }^{1}$ Examples include: Le Beau Derangement, 1967; Au bout de mon age, 1975; Priory: The Only Home I've Got, 1978; The Last Days of Living, 1980; The Business of Aging, 1981; The Forbes Home, 1982; The Last Right, 1984; Don't Take My Sunshine Away, 1991; When the Day Comes, 1991; Nurses Care: The Old Folks Down Home, 1992; You Won't Need Running Shoes Darling, 1996; Caregivers: Episodes one-four, 1997, and Labour of Love, 1998.

${ }^{2}$ The Eden Alternative is a registered approach to care that considers long-term care residences to be habitats in which forming community is the central goal. According to its principles, deinstitutionalization is possible and desirable even within what are commonly considered to be institutional settings. More information is available at edenalt.org 
indicate that the NFB continues to view care, and particularly care for seniors, as a valuable site both esthetically and in terms of social documentary. While Canadians take heightened interest in threats to their own socially funded health care system due to increasing economic pressures toward privatization, this article offers a Canadian example of an issue that is of international importance: how to care for older adults as the global population ages.

Intriguingly, while showcasing different models of care, both films also tell the stories of portrait photographers who have the explicit goal of capturing the experience of the patients/residents for a wider audience. Thus, these "creative treatments of actuality" also highlight spaces for creative production within care systems (Grierson 1932: 8). House Calls (Ian McLeod 2004) follows the work of Mark Nowaczynski, a physician who follows the tradition of social documentarian Lewis Hine who, in the early $20^{\text {th }}$ century, used photographs of child workers to challenge existing labor law. Nowaczynski photographs his elderly patients to support his arguments about funding for home care, aiming to illustrate dignity amid what he also perceives as fragility and vulnerability. A Year at Sherbrooke (Thomas Hale 2009) follows artists Thelma Pepper and Jeff Nachtigall who work with residents of a Saskatoon long-term care facility - Pepper photographs the residents and Nachtigall helps some of the residents to become visual artists themselves. In this article, I draw on the critical gerontological perspective that the stories told about aging play a significant role in transforming ways of approaching late life. ${ }^{3}$ I look at the relationship between the esthetic and the documentary commentaries offered by the two films in terms of that relationship's importance for the current Canadian care landscape.

Julia Twigg (2004) points out, "narratives of decline have replaced all other forms of meaning and interpretation of the body in later years,

\footnotetext{
${ }^{3}$ In particular, I refer here to the ways in which critical gerontologists, such as Hannah Zeilig (2011), Stephen Katz (1996), and Ruth Ray (2008), explain the "need to radically rethink the ways in which age and ageing have been culturally configured" (Zeilig 2011: 16), "rescue from obscurity the productive and transformative potential of the various cultural institutions that are populated by the elderly" (Katz 1996: 4), and "[cast] a critical eye on society and the field of gerontology itself" (Ray 2008: 97).
} 
International Journal of Ageing and Later Life

so that other more humanistic or plural readings become impossible" (61). This article proposes that these documentary films merit close analysis because they offer contradictory readings of the aging body that are not reductive and that, to differing degrees, embrace narratives of decline. Hannah Zeilig (2011) argues, "considering narratives of age (whether as teaching tools, to critique social policy and cultural norms or to explore biographical stories) represents one of the most interesting ways of provoking critical thought about ageing" (19). Similarly, Simon Biggs (2001) points out that "a narrative approach makes it much easier to sidestep social determinacy and take a stance toward positions that might otherwise present themselves as the only possible reality" (314). However, he is also clear about the limits set by a narrative approach: "the question becomes how far a narrative allows a stand to be taken and how convincing is the narrative in inviting a new terrain for struggle" (Biggs 2001: 314). In fusing commentary on photography with commentary on care practices, these films provoke critical questions about both, showing late life to be a misunderstood and underrepresented stage.

In putting forward views on aging and care within contemporary Canada, the films also reveal their own limits. House Calls determinedly shows an effective campaign to improve the medical care that isolated seniors received at home, showcasing the situation of individuals who otherwise would be at best invisible. However, House Calls does so at the expense of viewing the nursing home as a failure of the system, a desperate measure, or a last port of call. A Year at Sherbrooke embraces the possibilities within a habitat model of long-term residential care and goes further than offering images of its residents by offering them the opportunity to become visual artists themselves. However, the main interview subjects in A Year at Sherbrooke tend to be younger residents of the facility, so that the voices of older adults are not as prominent as they are in House Calls. Taken together, these two NFB productions offer an exciting view of how growing older within an institutional setting might be reconceived, for example, if Nowaczynski's passion for policy change and focus on isolated older adults were to meet Nachtigall's passion for seeing long-term care receivers as creative agents.

Because both films were produced within a national institutional context that has departed from, but is still influenced by, Griersonian documentary 
traditions, they bear clear traces of "the 'classic' documentary style" which "depends on the photographic basis of the film image as evidence of the actual existence of what it shows" (Leach \& Sloniowski 2003: 5). In his influential essay "What is an image?" W. J. T. Mitchell (1984) explains that "images are now regarded as the sort of sign that presents a deceptive appearance of naturalness and transparence concealing an opaque distorting and arbitrary mechanism of representation, a process of ideological mystification" (504). This description applies especially to the myth of photographic truth that infuses both the documentary form and the portrait photographs discussed in this article. Both House Calls and A Year at Sherbrooke showcase the constructed nature of the photographic image by situating photographers as central characters (and social actors). Nonetheless, even in their commentary on still photography, they depend on the notion that the portrait photographer is capturing a form of reality and they, for the most part, offer viewers a means by which to observe that process. Also, while these films do to some extent highlight the artistry of photography, or at least show the processes that produce photographs, they do not highlight the artistry of the documentary camera that is behind the film, even though a similar set of choices about film stock, lighting, positioning, and choreography have gone into both. This similarity invites this article's investigation of what Mitchell calls "ideological mystification $^{\prime \prime}$ offered by each film's images that appear natural but are highly staged.

\section{House Calls}

In House Calls, Nowaczynski describes the photographic portraits he takes of his patients as central to his tireless advocacy for an increase in Ontario's allowed billing ratio of home visits to office care. At the time of filming,

\footnotetext{
${ }^{4}$ In referring to "ideological mystification", I follow W.J.T. Mitchell (1984) (quoted earlier in the paragraph) who is talking about the ways in which images are read as not "transparent windows" but rather somewhat "deceptive" in appearing to be natural while in fact hiding the ways in which they are representations. This article offers context, through the documentary films, that gets at the ways in which the photographs of seniors within each film are careful creative constructions and not mere snapshots in time.
} 
International Journal of Ageing and Later Life

physicians could bill OHIP (Ontario Health Insurance Program) approximately twice as much for a house call compared to an office visit, but the time required for a house call was far more than double. Thus, doctors faced disincentives to adopt a mode of health care delivery that Nowaczynski finds necessary for some patients. To make this argument, Nowaczynski photographs what he describes as his patients' "plight", demonstrating that they are suffering at home due to a lack of adequate access to medical care and that without house calls they may not ever receive the medical attention they need. Since filming, Nowaczynski's photographs have been featured in exhibitions in such venues as the Royal Ontario Museum and Edmonton's Shaw Conference Centre. In 2012, Ontario's Action Plan for Health Care advocates for an expansion of doctors' house calls as part of a Seniors Care Strategy that supports home care initiatives. The lead physician for developing that strategy, Dr. Samir Sinha, works closely with Nowaczynski, and it appears that Nowaczynski's photographic advocacy was at least one key factor in changing both policy and funding. However, the initiative is part of the Liberal Party of Ontario's election promise to allocate more funding to support house calls by physicians and does not reflect a change to how much they can bill for that form of work, nor yet has it been transformed into legislated policy. Joining this incentive, the adoption of interdisciplinary family health teams could greatly increase the house calls practice. Nowaczynski formed such a fully funded care team (including a social worker, an occupational therapist, and a nurse practitioner) in 2009. However, he is still in the position of having to argue for the program's cost effectiveness and to convince other physicians to form teams, so that his advocacy continues in new directions.

House Calls presents three interwoven vignettes of isolated seniors whom Nowaczynski perceives to be dangerously frail. In this article, I draw attention to how director Ian McLeod frames Nowaczynski's portraiture and medical care within the broader context of the patients' homes, more overtly making a connection between the two practices of photography and medicine. Each opening segment begins with footage of a film negative and ends with Nowaczynski choreographing and taking a shot of the interview subject, followed by his return to the darkroom to transform the negatives into prints. Throughout, invisible interviewers prompt 
Nowaczynski's three patients to describe their living situations, their physical states, their pasts, their thoughts on death, and their thoughts on being old. Meanwhile, the interviewees are being treated medically and then photographed by Nowaczynski as well as filmed by the documentary camera operators, Michael Grippo and Mark Ellam.

The motion picture camera focuses on the surroundings, with close-ups of cobwebs, low angle shots of steep flights of stairs, and long takes of labored daily tasks. McLeod situates Nowaczynski's photographic and medical objects, his patients, as engaged in a range of modestly creative acts on a day-to-day basis - such as going through a surprisingly intricate adapted method of making coffee, carrying clothes down a daunting staircase, and figuring out how to pick up a beloved if obese cat. These acts all show the older adults adapting their surroundings and their activities to accommodate physical disabilities, though those adaptations are not the focus of the narration. Almost at odds with Nowaczynski's suggestion (that these seniors should remain living at home), these graphic details hint that another living situation might offer some clear advantages. That is, the inadequacy and difficulties of the various home spaces portrayed, framed differently, could be taken as an argument in favor of institutional care, if that care could provide opportunities to make one's own coffee and have pets. However, both Nowaczynski and McLeod honor their photographic subjects' expressed desire to remain living at home while presenting portraits of the frailty that must be addressed to make this a continuing viable option.

\section{Dr. Mark (Nowaczynski)}

McLeod's film concisely but clearly illustrates Nowaczynski's medical approach, explaining that Nowaczynski chooses to make home visits to his most frail patients because, as the doctor puts it, "If I didn't come see them, they wouldn't come and see me and so they wouldn't get any medical care". The audience witnesses him insistently coaching patient Connie to tell social services that she needs help bathing (though he realizes that she doesn't) because saying so will make her eligible for some funded home care supports. Similarly, he tries to alter patient Joe's prescription regimen while Joe talks about various other medical issues and blames the pills for 
International Journal of Ageing and Later Life

his dangerous dizziness. After the filmmakers devote an entire scene to demonstrating how arduous and physically painful it would have been for patient Ria to have continued visiting Nowaczynski at his office, the doctor is nonetheless forced to refer her to a specialist who does not make house calls, revealing the limits of his practice.

Such nuances are absent from the exhibits of still photographs mounted by Nowaczynski since those lack much of the context provided by the documentary film approach and are limited to Nowaczynski's purposeful view of his patients' frailty. The textual frames of the ROM exhibit, for example, include a media release that offers biographical descriptions of four "at risk" patients as well as careful interpretive lenses for reading the photographs. In one section, viewers are told, "In a portrait taken on a Sunday morning six weeks after [her husband's] death, you see Barbara sick with pneumonia and congestive heart failure. She was sitting in Ross's chair" (ROM 2010). The low light image shows Barbara seated in one of two matching armchairs in what appears to be a cluttered living room. There is no visual indication of her illness, besides a box of tissues, and no visual sign that it is her deceased husband's chair she has chosen to sit in over her own. The textual frame pushes a particular interpretation by offering biographical context. Nowaczynski's photographs, and ancillary materials, tend to convey an element of pathos without necessarily showing the active engagement the seniors have in contesting that view and their positioning, as conveyed by McLeod. Both the system and resistance to it are more present in the film than in the photographs, including their exhibition, even though shortcomings of the funding system are the primary motivation for the photographic exhibitions.

Throughout the film, Nowaczynski draws on the medical usage of the term "frailty" as shorthand for patients who require care and whose care will cost money. His usage comes from a biomedical perspective, though there are ongoing disputes about the usage of the term "frailty" even within the lexicon of geriatric medicine (Gilleard \& Higgs 2011). ${ }^{5}$

\footnotetext{
${ }^{5}$ Gilleard \& Higgs (2011) explain that the term "frailty", although it has become prominent within geriatric medicine, faces "definitional difficulties" because it resists measurement. However, they also note that there is "broad consensus" about a group of patients who can be labeled "frail" (476).
} 
Nowaczynski describes Connie as a "frail old lady with heart disease and partly blind" and explains Ria's agreement to have him visit her at home as "acceptance that she was frailer and less mobile than she thought she was". Dr. Mark, as Nowaczynski is affectionately called, speculates that Joe's reluctance to use a scooter has

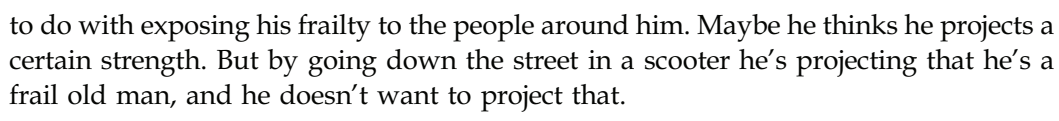
certain strength. But by going down the street in a scooter he's projecting that he's a frail old man, and he doesn't want to project that.

Not surprisingly, neither Ria, Connie, nor Joe describe themselves as frail, despite their references to continual excruciating pain. Joe might say, "I should chop my fuckin' legs off", but in saying this, he is not expressing vulnerability but rather distaste for his own physical state. Intriguingly, Nowaczynski's patients are most assertive when the doctor encourages or interprets an admission of frailty on their part.

The first and most obvious instance of a clash between an official story and an interview subject's alternate story occurs when Nowaczynski instructs Connie on how to handle an interview about her eligibility for home care. Speaking loudly and slowly, Nowaczynski asks her to tell him "the most important thing that she will have to accept in order to get home care". He refutes her initial answers, "money" and "dishes", with an insistence that she must accept help with bathing, despite the fact that, as she tells Nowaczynski, she has just bathed herself. Her stance appears to match what Amanda Grenier and Jill Hanley (2007) explain when they state, "Older women with limited resources are ... caught between the expectation of compliance (e.g. grateful receipt of limited services) and the implications of such classification and compliance" (218). In an attempt to negotiate bearable conditions, Connie learns that wearing her bathing suit during the process of being washed would not be an option. She momentarily proposes a version of what Nowaczynski needs her to say, "I guess you ... put up with it". But when Nowaczynski quizzes her one last time, Connie describes his requested answer as "a kick in the pants ... not quite". Nowaczynski does not acknowledge her joke but, rather, responds by repeating his instructions. In capturing this exchange, the filmmakers convey both Nowaczynski's perspective, wherein Connie is a deserving frail old lady who needs to live with her cat and so cannot 
International Journal of Ageing and Later Life

be moved into institutional care, as well as Connie's jests concerning acquiescence and resistance. Later, viewers learn that Connie is not able (or perhaps willing) to do as Nowaczynski has advised: she turns away the home care attendants from her door, insisting that she can do it alone, rejecting the implications of her compliance.

\section{Nowaczynski's Lens}

House Calls is as succinct about Nowaczynski's photographic practices as it is about his medical approach, focusing on the doctor's professional (medical) goals via photography rather than on technical matters or even esthetic goals. After McLeod presents an opening shot of negatives being processed in a darkroom, Nowaczynski cites the solitary lives of his patients explaining that "you" should "document what you see. This is a whole hidden world. These people live like hermits. Nobody knows they're there". He suggests that his photographs simply record what is "there". But the stark contrasts between McLeod's filmic portraits and Nowaczynski's static black and white images reveal that claim to be too limited. In the opening moments of the documentary, McLeod portrays Nowaczynski evaluating film negatives with a magnifying lens. McLeod offers a close-up of Nowaczynski's eye, which he follows to an extreme close-up of patient Joe's eye, glowing with negative light, which becomes the backdrop for the film title credit. In this way, McLeod emphasizes the way in which Nowaczynski portrays pathos. It is a fairly obvious point that photographs record a constructed static moment in time whereas documentary cinema, though similarly limited, can provide more context (Beattie 2004; Ellis \& McLane 2005; Nichols 1991). But this documentary film about Nowaczynski's photographs does not merely reveal their artifice. More significant, the film exposes and plays upon Nowaczynski's deliberate (perhaps admirable) attempt to situate otherwise dignified older adults as inviting pathos to make an argument for increased resources. As Bill Nichols (1991) says (speaking of dying bodies in documentary), "At stake is representing the indignities and hazards flesh is heir to with sufficient magnitude to escape the security of comfortable responses of charity or sympathy to martyrs and victims" (237). However, as Lucy Burke (2007) points out in a discussion of representing those with late-stage 
Alzheimer's disease, "one must ask what it would mean not to represent those with the disease, to shy away from the 'representation' of those at the limits of life" (62). While Burke is referring specifically to issues of consent, her point, taken with Nichols's, is also helpful in thinking about Nowaczynski's challenge of balancing the views of the public and of his patients.

The photo shoots interspersed among the interview segments starkly show the clash between the faces Nowaczynski needs to show the public and the individual subject's desired view. For example, Nowaczynski describes Mrs. Reynolds as a "vivacious, obstinate, strong-willed character". He tells viewers, "she's a whole person", accompanied by the footage of her crawling up an intimidating staircase while she explains that she is a "stubborn mule ... I don't want a fuss made about me, I just don't want it". This phrase elsewhere expresses her need to die in her house, but in this instance she is referring to Nowaczynski's photographs of her. She instructs him, "When you show it on the pictures, I don't want poor old Mrs. Reynolds, this that and the other". But as the film follows her back down the stairs, with clothes draped over her shoulders so that she can grip each bannister, and then on a painful journey to Nowaczynski's office, her fears of being portrayed as a figure of pity, but for her own subtle and obvious interventions, seem justified. When she is shown her portrait, Mrs. Reynolds is unimpressed, declaring, "You see, that's a bitchy face".

The other two interview subjects also express skepticism about being chosen as an esthetic object. Connie asks, "Who in the wide world want to see a bunch of pictures for me, of me ... junk". Joe demands, "What are you gonna do with these pictures, then? Make it a scrapbook and call it The Living Dead?" As Nowaczynski explains to the camera,

\footnotetext{
When you have no voice, you don't exist ... I think the photographs give them a voice and bring attention to their hidden plight and stimulate change. The photographs will open doors, open people's eyes and hopefully open people's hearts.
}

The photographs are not framed for the people they portray but for a wider uninitiated viewership. Nowaczynski publicly declares his goal of documenting a "hidden world" to make changes to policy on health care funding. In doing so, he casts the choice of institutional care as a failure. 
International Journal of Ageing and Later Life

Based on various untenable long-term residential care scenarios, he even goes so far as to imply that his patients die as the result of an undesired move to such a place. Thus, his goal in creating a scrapbook of the "Living Dead" is not solely esthetic but primarily aimed at preserving his patients' right and capacity to receive medical care at home.

\section{A Year at Sherbrooke}

A Year at Sherbrooke showcases a different model of care that imagines a long-term care facility as having the potential to be a viable and desirable setting. Thomas Hale, the director, makes insightful connections among the Eden Alternative Care Philosophy of the Sherbrooke Community Centre in Saskatoon, the photographic practices of Thelma Pepper, and the transformations experienced by residents who participate in artist-inresidence Jeff Nachtigall's drop-in art studio. The film showcases the collaboration between Nachtigall and Pepper, a photographer who has worked extensively with Sherbrooke residents, and between both of the artists and selected residents. The final scene of the film portrays the opening gala of a show of residents' work at the Mendel Art Gallery. By including the scene of this joyful event, Hale conveys that Sherbrooke residents remain part of a local community beyond their institutional home space. He also demonstrates one positive outcome of residents' engagement with visual art. It is impossible not to share resident Stewart's irrepressible elation as he realizes he can call himself an artist, publicly, for the first time.

\section{Pepper's Lens}

In A Year at Sherbrooke, Pepper (a visitor whose husband had resided at Sherbrooke) explains that she took up photography seriously at the age of 60 , when she "needed a challenge of some kind". Inspired by witnessing her husband on the second floor, which is a locked-down secure unit primarily for dementia patients, she seeks to gain the trust of the people she photographs, so that they know, as she puts it, "I'm not using them for my own sake". Pepper's photographs show relationships, engaging expressions, and a sense of what she refers to as spirit. Describing her love 
of portraits, she explains, "I want to photograph them when they're in an animated conversation, rather than just staring at you". While not all of her photographic subjects are seniors, Pepper declares that she has no interest in photographing "a 16-year-old blond, or something, because", she says, "to me they didn't have any character". Moved by her husband's experience, and confident that even during his dementia he always knew when she was there, Pepper states that one of her photographic goals is to prove that "even though these people had Alzheimer's disease, there was something there that was more important than that and there was a spirit there". As with House Calls, I draw attention here to how Hale, the film's director, situates Pepper's photographs within a context that values the same principles as her art, and by showing her engagement with residents next to Nachtigall's work with them, he aligns her work with creative production by emerging artist-residents. She appears in the film both as an important artist who conveys a valuable message about long-term care and as an art critic who comments on the role she sees artistic production playing in the wellbeing of the residents as they become visual artists themselves.

Like Nowaczynski's patients, Sherbrooke residents express skepticism or disappointment about themselves as esthetic objects. The film portrays a meeting between Pepper and Matt, a younger resident ${ }^{6}$ who is paralyzed as the result of a diving accident. Certain that she has managed to capture Matt's spirit during a prior animated conversation and photo shoot, she hands over a photograph saying "don't you think that's you?" Clearly struggling with his image, Matt feigns polite agreement but does not fool Pepper. Two subsequent moving interviews convey the distress caused by this interaction. Pepper is dismayed, not having experienced such a reaction before. She tells the interviewer, "I felt like crying myself". However, it is not so much her artistry that Matt dislikes. Rather, he expresses a discontent with his new appearance "because of the injury and stuff". While he does admire himself in a mirror toward the end of the film as he prepares for the art show, he never quite reconciles himself with

${ }^{6}$ The residents' ages are not given, but based on his appearance and behavior it is fair to assume that Matt is in his twenties. 
International Journal of Ageing and Later Life

Pepper's image of him, though eventually he does consent to having the photograph hung on his wall.

\section{The Human Habitat Model}

Director Hale ensures that Matt's discomfort with a new self that has seemingly been forced upon him as the result of injury permeates the film and resonates with struggles of other residents. Throughout the film, residents have the opportunity to speak with an off-camera interviewer about the experiences that brought them to long-term care, including their deep resentments of and despair about their situation. Matt ruminates on why he continues to smoke even though his reduced lung capacity makes it certain that doing so will be fatal. He admits, "there are days when I want to die. Where I feel that hopeless. That depressed. Where it's just too unbearable to be in a wheelchair". Another resident, Jack, ${ }^{7}$ paralyzed due to a bicycle accident, confesses "I've never been more unhappy and miserable in my life because of my disabilities ... I've lost everything, and my options are to grow old in this wheelchair or to go to Switzerland", where assisted suicide is legal. One reluctant participant in the art program expresses resentment of and resistance to Nachtigall, saying, "He reminds me of where I'd be if I was healthy again because it was about the age of 37 where I started to deteriorate".

The film portrays a fairly pleasant long-term care facility and showcases a unique feature: its artist-in-residence program. But it also captures the difficult emotions experienced by residents about their circumstances. Further, the film does not romanticize disability as a site of creative development nor as a state that can be overcome or overshadowed by artistic achievement. One of the most popular art works at the Mendel show portrays what is officially known as an "incontinence pad" attached to a canvas with the lettering DIAPER and an arrow painted in purple. As its creator explains, "God forbid that you call something a diaper and that's what it is. Why hush up the reality of what it is?" While the material

\footnotetext{
${ }^{7}$ Again, as the residents' ages are not given, it is not possible to say how old Jack is. However, it might be useful to note that he does have gray hair and appears to be quite a bit older than Matt.
} 
challenges of adjusting to disabled life feature prominently, an argument for home care (against life at Sherbrooke) does not appear as part of the expressed resentments. Importantly, though there are many other older residents at Sherbrooke who are not featured in the film, with one exception, the residents interviewed are much younger than the patients in House Calls, so they are quite different from the patients treated by Nowaczynski.

Nonetheless, both the film A Year at Sherbrooke and its interviewees are as resistant to the negative characteristics of institutionalization as House Calls and Nowaczynski are. Set up by opening shots of a dog running happily down the hallway of the institution, and a disabled man riding his bicycle indoors while grinning with delight, Suellen Beatty, Chief Executive Officer, explains that residents and workers "fight the legacy of efficient care for the masses", "struggling to move out of that hospital model into something that we would call home". Chaplain Ray Purdie describes "a learning community, a community that tries to keep growing" and that "the latest growth and change is [Nachtigall's] art project". Hale depicts workers' continual efforts to individualize care, whether by knowing that music will motivate a depressed patient or trying to prevent at-risk residents from being able to smoke. And the staff is not unrealistic about the challenges faced in making Sherbrooke an appealing home for residents. Beatty explains that Sherbrooke's focus on autonomy and developing residents into members of a community "creates a very real world that is pretty messy". Purdie acknowledges the feelings of loss experienced by each of the residents and the challenge of inviting them to be "engaged again in the world". While there is no reason to assume otherwise, the film does not demonstrate whether or not this sense of a hopeful future extends to the older residents at Sherbrooke, such as those whom Pepper is more interested in capturing in her photographs.

\section{Creative Engagement}

Nachtigall attributes the eventual success of his voluntary drop-in art program to the work that Pepper had already done at the institution. He points out that Sherbrooke displays her photographs on the walls in place of "the worst reproductions or posters or garage sale art" typical of 
International Journal of Ageing and Later Life

long-term residential care facilities. As he puts it, "by the time I came around to do this residency ... they were already warmed to the prospect of having an artist walking through those hallways". Nachtigall is motivated in his work at Sherbrooke by his own prior severe head injury after which he "began to see things in shapes and colours and composition where everything became a picture". He proposes, "My brain was just working completely different from a healthy brain, a normal brain, whatever that is". From that experience, he reasons that Alzheimer's residents' brains are "not broken, but just working in a different way". Nachtigall wants to "collaborate and work with" residents with dementia because he sees them as possessing "untapped wealth". While this perspective could become a romanticization of dementia, within Hale's broader film it is balanced by the previously discussed views, particularly Pepper's. Still, Nachtigall's work with such residents is barely portrayed.

While A Year at Sherbrooke does not showcase people with dementia as the central subjects or artists, the film makes an argument for the benefits of creativity to improve quality of life in long-term residential care. Jack, perhaps setting aside what he calls "the Swiss option", explains of his newfound artistic skill: "It's given me a new lease on life". Impressed with a painting by Stewart (another resident), Pepper exclaims, "you're a different person. I mean, you were just kinda dragging along before and maybe getting a game of golf in, but now you're just blooming". Matt also seems to change through his engagement with Nachtigall's art program, which he initially participates in by painting by mouth and then by working with an elaborate mechanism that attaches a paint brush to his wheel-chair as a sort of fifth wheel. He tells the interviewer, "When you create, you're using another part of your mind. Just to let it all flow. Just to drive in fluid motions and ... just to watch what I create ... It's another outlet for emotion maybe or spirit even. It's pretty cool".

\section{Conclusion}

Both House Calls and A Year at Sherbrooke rest upon the well-grounded assumption that living in institutionalized long-term care is a dreary medicalized fate more likely to cause harm than good. But, as Hale's film suggests, long-term care facilities are open to transformation as are the 
related health care systems that Nowaczynski sets out to conquer. Hale's film illuminates how a facility such as Sherbrooke works against residual traces of the nursing home without ignoring its negative force and without denying that its residents give up some independence by living there. He does not simply offer a sunny picture in which interdependence stands in for independence, but he also does not offer much insight about aging or seniors. Instead, he shows one outlet - through artistic production that long-term care residents can find for their frustrated emotions and energies, and he shows that engagement in such creative activities is far more than merely therapeutic. Importantly, he presents it as central to a transformed sense of self, one that most likely would not have taken place in the absence of the acquired disabilities he depicts.

By offering photographic images of seniors, the two films uncover some of the different roles that capturing images of aging can play. To Nowaczynski, there is a hidden world that must be exposed to enact a specific social change. In pleading his case for increased support for home care, he has to treat the people he has photographed as objects. Pepper's question for Matt, "don't you think that's you?" is transformed by Nowaczynski into a slightly different question for a broader public, expressed strongly in the film: Would you want this to be you? Pepper aims to expose what she calls "spirit", an aspect of the older adults she photographs that is too easily overlooked. Her goal is to convey a richer understanding of what late life might entail. While Pepper's photographs offer more perspective on older adults as full subjects than Nowaczynski's do, Hale's film does not pick up on those perspectives to the extent that McLeod does.

I have focused on these two films because, collectively, McLeod and Hale use the documentary form to interpret aging and care in Canada for Canadians. I welcome the ways in which they suggest that the Canadian cultural imaginary might allow visions of aging beyond mere decline. In doing so, they offer insight into the social, cultural, and political values that govern care of older adults in Canada in the $21^{\text {st }}$ century. McLeod showcases home care as the most desirable option whereas Hale demonstrates that a long-term residential care setting could also become something to desire. These two views need to be thought of as in dialog, so that ongoing battles between support for home care over long-term 
International Journal of Ageing and Later Life

residential care can shift to a focus on better ways to provide care across a spectrum. Hence, I support McLeod and Hale's combined views of the current care framework as flawed, in need of repair, and having the potential to be transformed, and I appreciate that they both use the medium of social documentary to showcase the role portrait photography might play in that sea change, offering what Grierson (1979) might call "inspiration, which is to say a very laborious, deep-seeing, deep sympathizing creative effort indeed" (41).

\section{Acknowledgements}

This article was presented at the $7^{\text {th }}$ International Symposium on Cultural Gerontology/inaugural conference of the European Network in Aging Studies in Maastricht. I am grateful to the conference organizers, to the audience members, and to anonymous reviewers who presented me with challenging and helpful questions. The article received support from the Social Sciences Humanities and Research Council of Canada (4122010-1004 Armstrong) and benefited from other research conducted with the support of the Canadian Institute of Health Research (CUK 103281 Fast).

\section{Filmography}

Hale, T. (2009). A Year at Sherbrooke. National Film Board of Canada. McLeod, I. (2004). House Calls. National Film Board of Canada.

\section{Corresponding Author}

*Sally Chivers, Department of English, Trent University, Ontario, Canada. Email: sallychivers@trentu.ca

\section{References}

Beattie, K. (2004). Documentary Screens: Non-Fiction Film and Television. New York, NY: Palgrave Macmillan.

Biggs, S. (2001). Toward critical narrativity. Journal of Aging Studies 15: 1-14. 
Burke, L. (2007). The poetry of dementia: Art, ethics, and Alzheimer's disease in Tony Harrison's Black Daisies for the bride. Journal of Literary Disability 1(1): 1-14.

Department of Justice (1985). National Film Act. Statutes of Canada C n-8.

Ellis, J. C. \& McLane, B. A. (2005). A New History of Documentary Film. London: Continuum International Publishing Group.

Gilleard, C. \& Higgs, P. (2011). Frailty, disability and old age: A reappraisal. Health: An Interdisciplinary Journal for the Social Study of Health, Illness and Medicine 15(5): 475-490.

Grenier, A. \& Hanley, J. (2007). Older women and "frailty": Aged, gendered and embodied resistance. Current Sociology 55(2): 211-228.

Grierson, J. (1932). The documentary producer. Cinema Quarterly 2(1): 8.

Grierson, J. (1979). First principles of documentary. In F. Hardy (ed.), Grierson on Documentary (pp. 35-46). London: Faber and Faber Limited.

Katz, S. (1996). Disciplining Old Age: The Transformation of Gerontological Knowledge. Charlottesville, VA: University Press of Virginia.

Leach, J. \& Sloniowski, J. (2003). Introduction. In J. Leach \& J. Sloniowski (eds.), Candid Eyes: Essays on Canadian documentaries (pp. 3-12). Toronto: University of Toronto Press.

Mitchell, W. J. T. (1984). What is an image? New Literary History 15(3): 503-537.

Nichols, B. (1991). Representing reality. Bloomington. IN: Indiana University Press.

Ray, R. E. (2008). Coming of age in critical gerontology. Journal of Aging Studies 22(2): 97-100.

ROM (2010). House calls with my camera: Social documentary portraits by Dr. Mark Nowaczynski. Royal Ontario Museum. Available on http:/ / www.rom.on.ca/news/releases/public.php?mediakey= wyau2s01zp (Accessed: August 20, 2012).

Turcotte, M. \& Schellenberg, G. (2006). A Portrait of Seniors in Canada. Ottawa: Statistics Canada.

Twigg, J. (2004). The body, gender, and age: Feminist insights in social gerontology. Journal of Aging Studies 18(1): 59-73.

Zeilig, H. (2011). The critical use of narrative and literature in gerontology. International Journal of Ageing and Later Life 6(2): 7-37. 